\title{
Lack of Patient Knowledge Regarding the Adverse Effects of Analgesics With High Doses Leading to Elevation of Creatinine and Major Consequences - A Case Report
}

\author{
Krishna Teja Challa ${ }^{1}$, Sateesh Babu Arja ${ }^{2}$, Mirela Ponduchi ${ }^{3,4}$, Baby M. Snigdha ${ }^{5}$ \\ 1. Department of Medicine and Reserach, Avalon University School of Medicine, Willemstad, CUW 2. Medicine / \\ Clinical Skills, Avalon University School of Medicine, Willemstad, CUW 3. Department of Internal Medicine, Phoenix St. \\ Luke's Hospital, Phoenix, USA 4. Internal Medicine, Mountain Vista Medical Center, Mesa, USA 5. Internal Medicine, \\ St. James School of Medicine, Arnos Vale, VCT
}

Corresponding author: Sateesh Babu Arja, sarja@avalonu.org

\begin{abstract}
We present a case of a 49-year-old male with complaints of back pain and not being able to urinate. The patient was suffering from back pain for the last four days and followed up with the chiropractor, but the pain persisted. The patient took eight ibuprofen tablets $(1600 \mathrm{mg})$ within those four days to relieve the pain. Lab workup showed a blood urea nitrogen (BUN) of $175 \mathrm{mg} / \mathrm{dL}$, creatinine level of $32.87 \mathrm{mg} / \mathrm{dL}$, and an anion gap metabolic acidosis. With close monitoring and dialysis in the hospital, the creatinine came down to $11.92 \mathrm{mg} / \mathrm{dL}$. Ultrasound-guided renal biopsy showed that the patient developed acute interstitial nephritis. The patient was treated with prednisone and later discharged with a creatinine level of $8.60 \mathrm{mg} / \mathrm{dL}$. Before he was discharged, he was declared to have end-stage renal disease and placed on outpatient dialysis. Only a few case reports are recorded in the literature with such a high elevation of creatinine levels.
\end{abstract}

Categories: Emergency Medicine, Internal Medicine, Nephrology

Keywords: analgesics, nsaids, dialysis, interstitial nephritis, creatinine

\section{Introduction}

With an estimated daily usage of $>30$ million doses, nonsteroidal anti-inflammatory drugs (NSAIDs) are among the most common classes of medication used worldwide. NSAIDs work by suppressing prostaglandin (PG) synthesis, which then inhibits the enzyme cyclooxygenase (COX) and exerts its analgesic, antipyretic, and anti-inflammatory effects. The NSAIDs are known to have damaging effects on the kidneys and gastrointestinal tract when taken in large doses. Approximately 2.5 million Americans have been reported to have NSAIDs-mediated renal damage yearly [1]. There have been more than 70 million prescriptions written annually for NSAIDs in the United States alone, and they are also bought over the counter. It was estimated that more than 29 million US adults were using NSAIDs regularly in 2010 , which was a $41 \%$ increase from 2005. A self-reported study of over-the-counter and prescribed use of ibuprofen, which falls into the class of NSAIDs, noted that $90 \%$ took it regularly. In comparison, $37 \%$ took other forms of NSAIDs in addition to ibuprofen, and $11 \%$ exceeded the daily recommended limit of ibuprofen [2]. This case report emphasizes the Review ended 10/07/2020 Published 10/10/2020

\section{() Copyright 2020}

Challa et al. This is an open access article distributed under the terms of the Creative Commons Attribution License CC-BY 4.0., which permits unrestricted use, distribution, and reproduction in any medium, provided the original author and source are credited.

\section{Case Presentation}

A 49-year-old male patient without any significant past medical history presented to our hospital with problems of not voiding his bladder and back pain. The patient reported his back pain began four days ago when he was at work and tried to lift a $100 \mathrm{lb}$ instrument. The patient went to see a chiropractor, but there was no improvement with his back pain. He then started to experience left thigh and buttock pain along with the back pain for which he took eight ibuprofen tablets a day (1600 mg) for four days before presenting to the hospital. He denies taking ibuprofen for any other pain that he experienced in the past.

While in the emergency room, the initial labs revealed creatinine of 32mg/dL, BUN of 175mg/dL, Na of 128 $\mathrm{mEq} / \mathrm{L}$, $\mathrm{K}$ of $4.5 \mathrm{mmol} / \mathrm{L}, \mathrm{Cl}$ of $90 \mathrm{mEq} / \mathrm{L}, \mathrm{Co} 2$ of $17.0 \mathrm{mEq} / \mathrm{L}$, anion gap of 21 , Ca of $7.9 \mathrm{mEq} / \mathrm{L}$, and a total creatine kinase of 1315 micromoles/L. His liver function tests (LFTs) were also elevated - serum aspartate aminotransferase (AST) was 104 units, and alanine aminotransferase (ALT) was 281 units. His urinalysis showed 3+ blood and 2+ protein but 0-5 red blood cells. Left lower extremity Doppler ultrasound was negative for deep vein thrombosis (DVT). CT scan of the abdomen was unremarkable. There was fatty infiltration of the liver and thickening of the bladder wall, and diffuse soft tissue edema involving the left hip. The patient was given ondansetron hydrochloride (Zofran ${ }^{\circledR}$ Injection) 4 mg intravenously (IV) Q6H PRN for nausea, oxycodone hydrochloride (Roxicodone ${ }^{\circledR}$ ) $5 \mathrm{mg}$ PO Q4H PRN for pain, morphine sulfate $2 \mathrm{mg}$ IV Q2H PRN for severe back pain, hydralazine hydrochloride (Apresoline ${ }^{\circledR}$ Injection) $10 \mathrm{mg}$ IV Q4H PRN for hypertension, ceftriaxone sodium $1 \mathrm{gm} /$ (sodium chloride) $100 \mathrm{mls}$ at $200 \mathrm{mls} / \mathrm{hr}$ IV Q24H at $1900 \mathrm{SCH}$ for 
cystitis, and sodium bicarbonate $150 \mathrm{meq} /$ (dextrose) 1,150 mls at $150 \mathrm{mls} / \mathrm{hr}$ IV, Q7H40M SCH. Acute kidney injury and metabolic acidosis was the impression on evaluation in the ED.

Later the patient was moved to the telemetry unit to be followed up with the hospitalist. The patient was monitored by an internist, and a nephrology consultation was requested. On the following day, during the nephrology consultation, the patient's laboratory values were as shown in Tables 1-3. The patient's vitals are mentioned in Table 4. CT scan and renal ultrasound of the kidneys were ordered. CT scan of the abdomen was unremarkable. The nephrologist's recommendation was to continue the patient on the IV fluids with bicarbonate and avoid nephrotoxins. The nephrologist closely monitored the patient, and the plan was to place the patient on temporary dialysis if the kidney function doesn't show improvement.

\begin{tabular}{|c|c|c|c|c|c|c|c|}
\hline Labs & $\begin{array}{l}\text { On } \\
\text { admission }\end{array}$ & $\begin{array}{l}\text { Next } \\
\text { day }\end{array}$ & $\begin{array}{l}1^{\text {st }} \text { round of } \\
\text { hemodialysis }\end{array}$ & $\begin{array}{l}4^{\text {th }} \text { round of } \\
\text { hemodialysis }\end{array}$ & $\begin{array}{l}\text { Diagnosis } \\
\text { of AIN }\end{array}$ & $\begin{array}{l}7^{\text {th }} \text { round of } \\
\text { hemodialysis }\end{array}$ & $\begin{array}{l}\text { On the day of } \\
\text { discharge }\end{array}$ \\
\hline WBC & 9.0 & 11.7 & 14.0 & 11.8 & 12.1 & 11.8 & 12.9 \\
\hline RBC & 4.38 & 3.18 & 3.43 & 3.43 & 3.09 & 3.05 & 3.09 \\
\hline $\mathrm{Hbg}$ & 14.2 & 13.6 & 10.1 & 11.0 & 9.9 & 9.7 & 9.9 \\
\hline Hct & 39.3 & 28.4 & 29.6 & 31.1 & 28.5 & 27.8 & 28.5 \\
\hline MCV & 89.7 & 88.8 & 93.1 & 90.7 & 92.0 & 91.1 & 92.2 \\
\hline $\mathrm{MCH}$ & 32.4 & 31.7 & 32.0 & 31.8 & 32.0 & 31.5 & 32.0 \\
\hline MCHC & 36.1 & 34.1 & 35.4 & 34.9 & 34.7 & 34.9 & 34.7 \\
\hline RDW & 13.4 & 12.3 & 12.4 & 12.3 & 12.0 & 12.0 & 12.0 \\
\hline $\mathrm{Na}$ & 128 & 128 & 133 & 134 & 133 & 135 & 137 \\
\hline K & 4.5 & 4.1 & 4.5 & 4.2 & 4.7 & 4.7 & 4.4 \\
\hline Cl & 90 & 88 & 96 & 98 & 97 & 97 & 100 \\
\hline Co2 & 17.0 & 18.0 & 28.0 & 24.0 & 27.0 & 28.0 & 28.0 \\
\hline Anion gap & 21 & 22 & 9 & 8 & 9 & 8 & 9 \\
\hline BUN (mg/dL) & 175 & 171 & 60 & 37 & 39 & 37 & 18 \\
\hline $\begin{array}{l}\text { Creatinine } \\
\text { (mg/dL) }\end{array}$ & 32.87 & 30.2 & 18.60 & 11.92 & 14.29 & 10.80 & 8.60 \\
\hline $\mathrm{Ca}$ & 7.9 & 7.3 & 7.7 & 7.9 & 8.7 & 8.7 & 8.9 \\
\hline Phosphorus & 11.60 & 11.6 & 8.9 & 9.5 & 9.0 & 9.5 & 7.0 \\
\hline CK & 1315 & - & - & - & - & - & 300 \\
\hline $\begin{array}{l}\text { Est GFR (Afr } \\
\text { Amer) }\end{array}$ & 2 & 2 & 5 & 5 & 4 & 6 & 8 \\
\hline $\begin{array}{l}\text { Est GiR (Non- } \\
\text { Afr Amer) }\end{array}$ & 2 & 2 & 4 & 4 & 4 & 5 & 7 \\
\hline AST & 25 & 24 & 22 & 17 & 17 & 16 & 16 \\
\hline ALT & 90 & 85 & 65 & 54 & 49 & 45 & 46 \\
\hline BUN/ Cr & 5.32 & 5.6 & 4.7 & 3.10 & 2.72 & 3.42 & 2 \\
\hline
\end{tabular}

\section{TABLE 1: Patient's hematologic laboratory findings}

WBC - white blood cells; RBC - red blood cells; Hbg - hemoglobin; Hct - hematocrit; MCV - mean corpuscular volume; MCH - mean corpuscular hemoglobin; MCHC - mean corpuscular hemoglobin concentration; RDW - red cell distribution width; BUN - blood urea nitrogen; CK - creatine kinase; Est GFR - estimated glomerular filtration rate; AST - serum aspartate aminotransferase; ALT - alanine aminotransferase; AIN - acute interstitial nephritis 


\section{Cureus}

\begin{tabular}{|l|l|l|l|}
\hline Labs & On admission & On the $7^{\text {th }}$ round of hemodialysis & On the day of discharge \\
\hline Urine color & Yellow & Yellow & Yellow \\
Urine clarity & Clear & Clear & Clear \\
Urine PH & 6.0 & 6.0 & 6.0 \\
Urine specific gravity & 1.020 & 1.010 & 1.010 \\
Urine protein & $2+$ & $2+$ & $2+$ \\
Urine glucose & Trace & Trace & Trace \\
Urine ketones & Negative & Negative & Negative \\
Urine squamous epithelial cells & Rare & Rare & Rare \\
Urine RBC & Rare & Rare & Rare \\
Urine WBC & $5-10$ & $5-10$ & $2-5$ \\
\hline
\end{tabular}

\section{TABLE 2: Patient's urine findings}

RBC - red blood cells; WBC - white blood cells

\section{Labs}

ANCA reference labs

Negative

C-ANCA antibody

$<1: 20$

Proteinase 3 (PR3) antibodies

Atypical P-ANCA

$<1: 20$

P-ANCA antibody

$<1: 20$

Anti-myeloperoxidase

$<9.0$

Glomerular basement membrane antibody

Pending

\section{TABLE 3: Patient's immunology findings}

ANCA - antineutrophil cytoplasmic antibodies; C-ANCA - cytoplasmic antineutrophil cytoplasmic antibodies; P-ANCA - perinuclear antineutrophil cytoplasmic antibody

\begin{tabular}{|c|c|c|c|}
\hline Vitals & Emergency room & In telemetry unit & At the time of discharge \\
\hline Temperate & $36.4 \mathrm{C}$ & $36.6 \mathrm{C}$ & $36.6 \mathrm{C}$ \\
\hline Pulse & $65 / \mathrm{min}$ & $60 / \mathrm{min}$ & $68 / \mathrm{min}$ \\
\hline Blood pressure & $142 / 68 \mathrm{~mm}$ of $\mathrm{hg}$ & $132 / 78 \mathrm{~mm}$ of $\mathrm{hg}$ & $130 / 70 \mathrm{~mm}$ of $\mathrm{hg}$ \\
\hline Respiratory rate & 18/min & $16 /$ min & $17 / \min$ \\
\hline Pulse oximetry & $94 \%$ sat & $98 \%$ sat & $98 \%$ sat \\
\hline
\end{tabular}

\section{TABLE 4: Patient's vitals}

On a subsequent day on follow up with the internist, the kidney function tests were not improving; upon discussion with the nephrologist, a temporary dialysis catheter order was placed. On the same day, an 


\section{Cureus}

interventional radiologist placed a right internal jugular vein (IJV) temporary dialysis catheter, and the patient went for the first round of hemodialysis treatment, after which the creatinine level went down to 18 $\mathrm{mg} / \mathrm{dl}$. Urinalysis was positive for protein and red blood cells, and the labs of creatine phosphokinase (CPK) 1315 micromoles/L pointed towards rhabdomyolysis. The next day during the nephrology consultation, it was recommended to go for the second round of hemodialysis. The patient's lab showed phosphorus of $11.60 \mathrm{mg} / \mathrm{dL}$, leading to sevelamer $800 \mathrm{mg}$ PO TID initiation. The patient underwent another four rounds of hemodialysis, and the kidney function tests showed a creatinine level of $11.92 \mathrm{mg} / \mathrm{dL}$.

The patient subsequently went through hemodialysis for the seventh time, but his kidney function had not yet returned to the normal level. The nephrologist ordered a tunneled dialysis catheter to be placed on the patient to be able to receive outpatient dialysis once he is discharged, which was also placed by an interventional radiologist. His labs were checked again, and the results showed that his CPK, hyponatremia, and hyperkalemia were resolving to normal, but the creatinine stayed stable at a high level of $10.6 \mathrm{mg} / \mathrm{dL}$. Due to the lack of improvement in the kidney function tests towards normal range, the nephrologist ordered a renal biopsy. A day later, a kidney biopsy was done (Figure 1), which showed acute interstitial nephritis with very minimal chronicity, and the patient was started on prednisone $60 \mathrm{mg}$ once a day. Because of the lack of improvement on the kidney function test to normal levels, the patient was declared to have end-stage renal disease and was discharged with the outpatient dialysis treatment program and to follow up with the nephrologist.

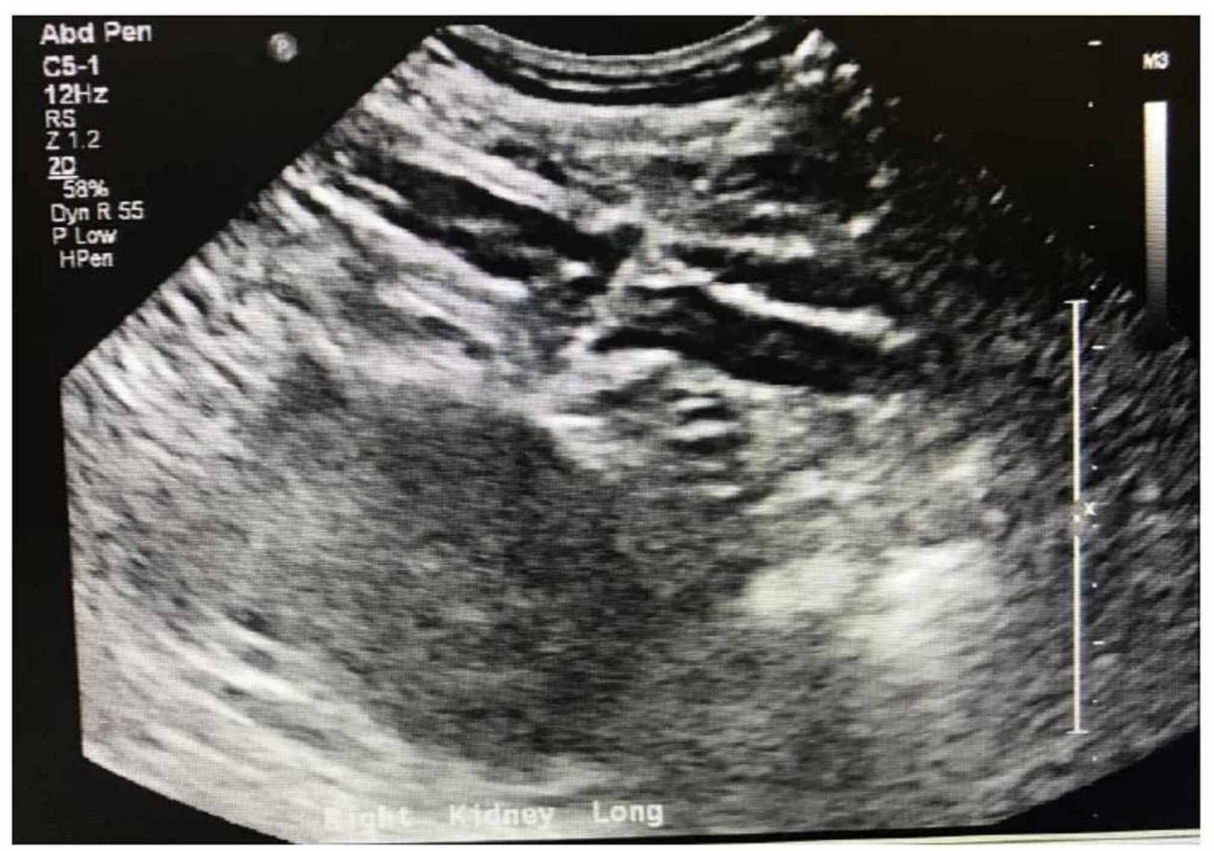

\section{FIGURE 1: Ultrasound-guided needle biopsy of the right kidney}

\section{Discussion}

Creatinine levels are used to assess the kidney's functioning, along with the glomerular filtration rate (GFR) and BUN. As creatinine is a waste product of our muscles, its levels are dependent upon the person's age, gender, and race, but average creatinine levels should be between $0.6-1.3 \mathrm{mg} / \mathrm{dL}$. Acute kidney injury occurs when there is damage to the kidney within a few hours or days. As a result, waste products start building up in our body, which can then be measured by the serum creatinine level. There were previously only four reported cases on creatinine levels being too high [3], and with our patient, we are able to add another case.

Studies have shown that NSAIDs' initiation was associated with an increased number of hospitalizations with acute kidney failure [4]. They cause acute kidney injury in patients who take them when they suffer from acute or chronic pain. Many people are not aware of the side effects of NSAIDs can have on the body, especially the kidneys, and the dose limit at which they can consume it. Because NSAIDs are freely available over-the-counter, these drugs' adverse effects are unregulated and underrecognized as drug agents that are potentially dangerous to take at large doses [4]. This was the case of our patient, who unknowingly took 1600 $\mathrm{mg}$ of ibuprofen, which led to his kidney damage.

By the time our patient found out something was wrong because he could not urinate, it was too late for him as damage to his kidney already occurred. He was seen by the nephrologist who recommended hemodialysis in the hospital to see if his creatinine can be brought back down to a near-normal level, which failed after 
hemodialysis courses, and the patient was eventually sent home with regular visits to the nephrologist for outpatient dialysis. Due to the lack of knowledge on the proper dose of NSAIDs use, action has been taken over the recent years to spread discussion about the serious matter at hand. Nonpharmacologic and pharmacological interventions other than NSAIDs have been emphasized when dealing with pain [5]. Our case highlights the need for the importance of public awareness regarding the adverse effects associated with the use of NSAIDs, especially high doses of NSAIDs.

\section{Conclusions}

Many over-the-counter (OTC) medications are readily available for people to purchase when they suffer from mild illnesses without a physician's need for a prescription. NSAIDs are among those readily available OTC medications that can relieve mild pain and cause kidney injury when taken in large doses. Our case report emphasizes the need for patient education regarding the adverse effects associated with the use of high doses of NSAIDs and the importance of finding innovative research on different treatment options for pain, such as other pharmacological and nonpharmacological treatments.

\section{Additional Information \\ Disclosures}

Human subjects: Consent was obtained by all participants in this study. Conflicts of interest: In compliance with the ICMJE uniform disclosure form, all authors declare the following: Payment/services info: All authors have declared that no financial support was received from any organization for the submitted work. Financial relationships: All authors have declared that they have no financial relationships at present or within the previous three years with any organizations that might have an interest in the submitted work. Other relationships: All authors have declared that there are no other relationships or activities that could appear to have influenced the submitted work.

\section{References}

1. Hörl WH: Nonsteroidal anti-inflammatory drugs and the kidney . Pharmaceuticals. 2010, 3:2291-2321. 10.3390/ph3072291

2. Nelson DA, Marks ES, Deuster PA, O'Connor FG, Kurina LM: Association of nonsteroidal anti-inflammatory drug prescriptions with kidney disease among active young and middle-aged adults. JAMA Netw Open. 2019, 2:e187896. 10.1001/jamanetworkopen.2018.7896

3. Asif AA, Hussain H, Chatterjee T: Extraordinary creatinine level: a case report. Cureus. 2020, 12:e9076. 10.7759/cureus. 9076

4. Chou CI, Shih CJ, Chen YT, et al.: Adverse effects of oral nonselective and cyclooxygenase-2-selective NSAIDs on hospitalization for acute kidney injury: a nested case-control cohort study. Medicine. 2016, 95:e2645. 10.1097/MD.0000000000002645

5. Dixit M, Doan T, Kirschner R, Dixit N: Significant acute kidney injury due to non-steroidal antiinflammatory drugs: inpatient setting. Pharmaceuticals. 2010, 3:1279-1285. 10.3390/ph3041279 